\title{
Quality of Experience Assessment of Banking Service
}

\author{
Mehran Junejo $^{1}$, Asif Ali Laghari ${ }^{2 *}$, Awais Khan Jumani ${ }^{1}$, Shahid Karim ${ }^{1}$, Mansoor Ahmed Khuhro ${ }^{2}$ \\ ${ }^{1}$ Faculty of Science and Technology, ILMA University, Karachi, Sindh, Pakistan \\ ${ }^{2}$ Department of Computer Science, Sindh Madressatul Islam University, Karachi, Pakistan \\ Email: junejomehran@gmail.com, asif.laghari@smiu.edu.pk, awaisjumani@yahoo.com, shahidhit@yahoo.com, \\ mkhuhro@smiu.edu.pk
}

Received: 10 April 2020; Accepted: 24 June 2020; Published: 08 December 2020

\begin{abstract}
In this paper, Quality of Experience (QoE) is used to assess and improve Bank's customer satisfaction and provide quality of service (QoS) according to their demands. QoE based web platform was developed for the assessment of customer satisfaction. The Eclipse Neon Enterprise Edition was used for the design and development of platform and MySQL database was used for backend database storage. The front interface of the platform provided user facility to enter their complaints and information, which will store in the database. The stored data will be used for the analysis of a particular employee's evaluations of his performance and behavior with customers. Management can observe the performance of the bank's employees and can overcome their flaws by providing the required training. If one employee is lacking communication skills and is unable to convey his message to the customer of the bank, then the management can arrange training for improving his/her communication skills.
\end{abstract}

Index Terms: Quality of Experience (QoE), Bank, Quality of Service (QoS), Performance.

\section{Introduction}

In the past few years, Quality of Experience (QoE) has attracted a lot of researchers and has become an important research domain. QoE is about observing human experience in business and technology usage $[1,2]$. It helps to improve the performance, efficiency, and effectiveness of users on using services or products [3, 4]. QoE is used in different domains such as video streaming, online gaming, image processing, and quality assurance. Other domains such as telecommunication use QoE to optimize the network and product services $[5,6,7]$. Cloud gaming and online video streaming are using QoE more than most of the other domains [8, 9].

There are several commercial and noncommercial banks are working under the rules and regulations of the state bank of Pakistan [10, 11]. Some of the largest banks of Pakistan are National Bank of Pakistan (NBP), Habib Bank Limited (HBL), United Bank Limited (UBL), Allied Bank Limited (ABL), Meezan Bank, Bank-Al-Habib (BAHL) and Bank-Al-Falah (BAFL), Muslim Commercial Bank (MCB) and some small microfinance banks and also the number of banks is growing rapidly every day [12]. These banks are providing lots of facilities to their customers both account holders and non-account holders. Facilities may be including cash deposit and withdrawal, Debit and Credit Card facilities, Foreign Remittance [13, 14]. More people are operating an account these days and the number is increasing every day. Even if the customer does not have a bank account, they still come to the bank's branches for the payment off bills and to ask for loans [15]. Non-account holder customers are considered to be equally important for the bank as they also do financial transactions and banks earn profit from their transactions without providing additional facilities as they provide to the account holders customers. Assessment of customer satisfaction still issues for banks and user share their ideas on social networks, which damage the reputation of the bank as well as decrease the revenue [16].

The purpose of this research is to improve customer satisfaction of banks around the world and enjoyment through Enhancing QoE. Most banks in Pakistan are working very hard to improve their services and standard by training their employees and by introducing new products to enhance customer satisfaction and trust. In the banking industry, QoE can be characterized in lots of factors that are the experience of Employee with the bank or experience of the customer with the bank's services and products. QoE varies from person to person as every human is different from another human. We use QoE to analyze how many customers of the bank are satisfied with the employees serving them. Techniques like interviews and surveys can be used to observe and analyze the QoE. This application will be very useful for most of the banks in world to improve the quality of their services and observe the customer's QoE and how much customers are satisfied with the bank's services. QoE will be used for improvement in employee's performance 
after getting feedback from Bank's customers and Bank's higher management can also use QoE to measure the quality of services (QoS) provided by the employee of the bank.

The contribution of the paper is follows:

The design and development of QoE based web platform for the baking sector to assess customer feedback.

$>$ MySQL database is used in the backend to store and retrieve data for the analysis of employee's performance.

This paper organized into 5 sections and section 2 is providing literature of QoE. In section 3, we provided details of the design and development of the QoE collection framework for banks and assessment of customer experience about the bank's employee. Section 4 is based on the results and discussion of the developed framework and finally, in section 5 , we conclude our research work and provide future direction.

\section{Literature Review}

QoE was used in different domains to get user reviews about the products and improve the services. QoE studies were not conducted on the banking side yet, so the literature referred in this paper is based on the QoE utilization in the other research field to assess the customer satisfaction on a particular parameter and upgrade system to fill user needs $[17,18,19]$. According to Wang et al. QoE is highly related to customer satisfaction and QoS is related to company policies. QoE is based on customer reviews, comments about the particular service of the organization. QoS is about technical data of communication networks or the level of service provided by any organization to customers [20, 21].

Furthermore, Laghari et al. [22] have assessed subjective QoE for products is used by organizations, which are considered to be costly and are a bit confusing for the vendors to understand the feedback whether it's positive or negative. Additionally, it is easy to capture the data in subjective compared to the objective. Similarly, it has proposed vendors changed technical parameters to improve their services, but service level agreement still has problems to satisfy their users. Additionally, the researcher has explored fix policy of organization for a long period and users want changes time by time is the reason product deployment or development and services delivery must be merged as service level agreement is signed by both the service provider and Client.

Similarly, Laghari et al. have surveyed to analyze better QoE at different resolutions and file formats were used [23]. Different parameters were used to collect QoE of the user to assess the quality of video for better performance of online streaming formats. The results show that the resolution of videos was increased, then the user's QoE is also increased, and 3GP format provides better quality for lower resolution for mobile devices. During the research, the author has surveyed that all frameworks did not support the subjective and objective QoE assessment. EQoM is only that support all the multimedia services and framework was proposed for multimedia, this framework can be used for data analysis, policy change support, monitoring, and deployment [24].

Similarly, Laghari et al. have investigated during experiments and assessments, different quality videos having different resolution and bitrate were posted on cloud environment on two different locations nearby and one on a very long distance [25]. The delay time of the network was calculated by using the ping command. Users watch and perceive these videos and provided their QoE. The results showed that nearby locations got higher ratings as compared to the long-distance clouds. Delay of network traffic was caused by the long distanced cloud.

Furthermore, the researcher has conducted the QoE assessment experiment, data were taken with 134 students, and around 65 percent of them were females, aged in their 20's. Most of the students were from computer science and others belonged to different departments. Students were from both postgraduate and undergraduate. In a questionnaire, students were asked to provide their information and rate the quality of the video, which was shown to them in online play. The results show that user-provided high ratings to original videos as a compressed video of social clouds. Twitter compressed more to videos as compared to other social clouds and Facebook provides better visual quality after compression of the original video [6].

The primary purpose of this research and study was to propose a customer feedback management system (CFMS) and to develop an application system for the banks that can help most of the banks in the world. To the best of our knowledge, no research work was done on observing customer's QoE in any banking branch of the world.

\section{Methodology}

Eclipse Neon Enterprise Edition is the integrated development environment (IDE), which was used to develop, debug and test the application project [26, 27]. The reason behind using Eclipse IDE is that it is free of cost and is open source and provides an Industrial level of development. It supports many other languages other than JAVA. Easy to use and simple to develop rapid application either desktop or web application and also Eclipse offers very useful extensions and plugins. The screenshot of the Eclipse Neon Enterprise Edition is given in Figure 1. 


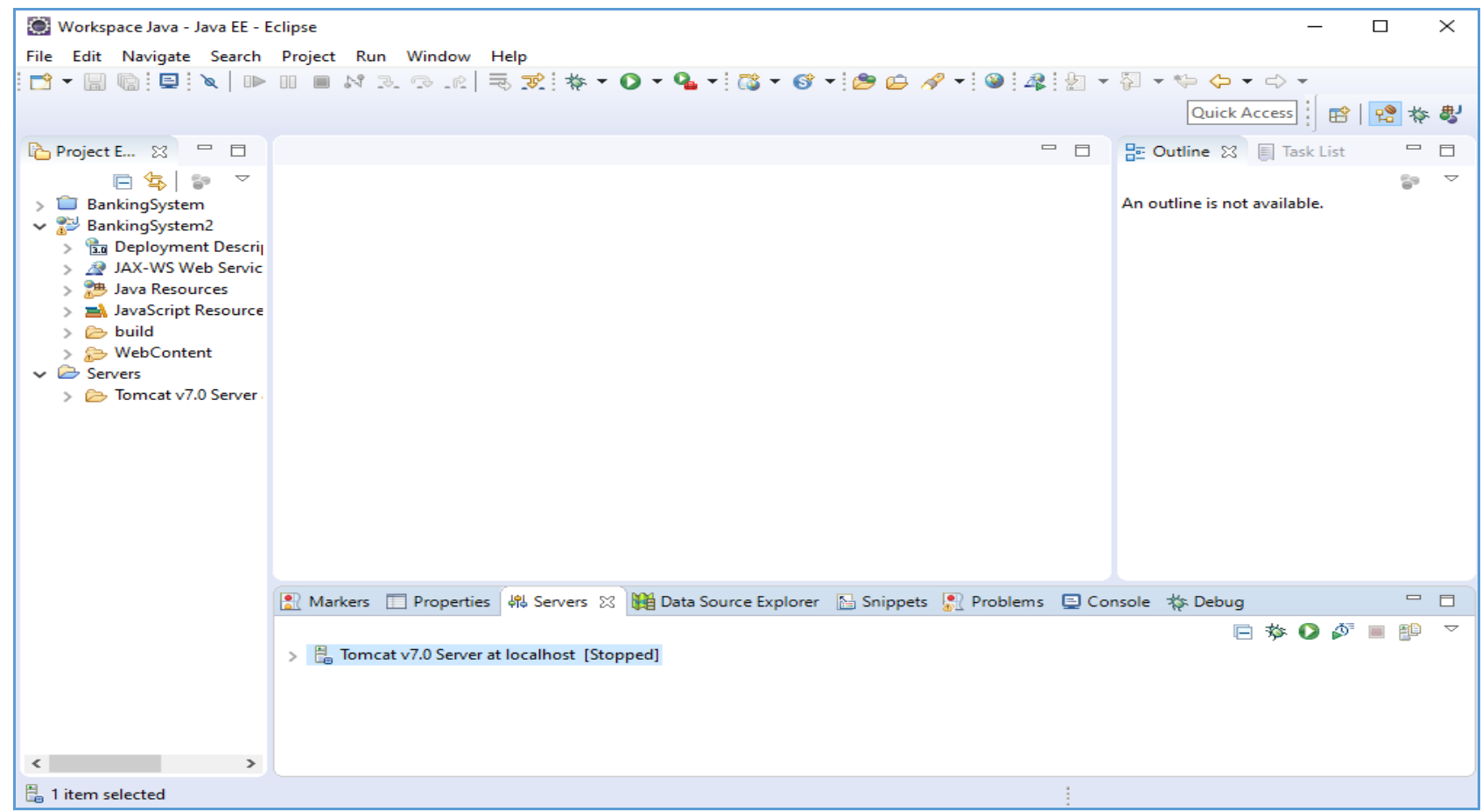

Fig. 1. Shows the Eclipse IDE

MYSQL version 5.5.43 is used to create Database Structure and tables [28, 29]. For the front user interface of MYSQL SQLyog version, 11.33 were used. The reason behind using MYSQL is an open-source database and it is a relational database management system (RDBMS). It has Flexibility of Open Source Database and provides basic features that are free of cost. Figure 2 shows the SQLyog displaying the infrastructure of MySQL.

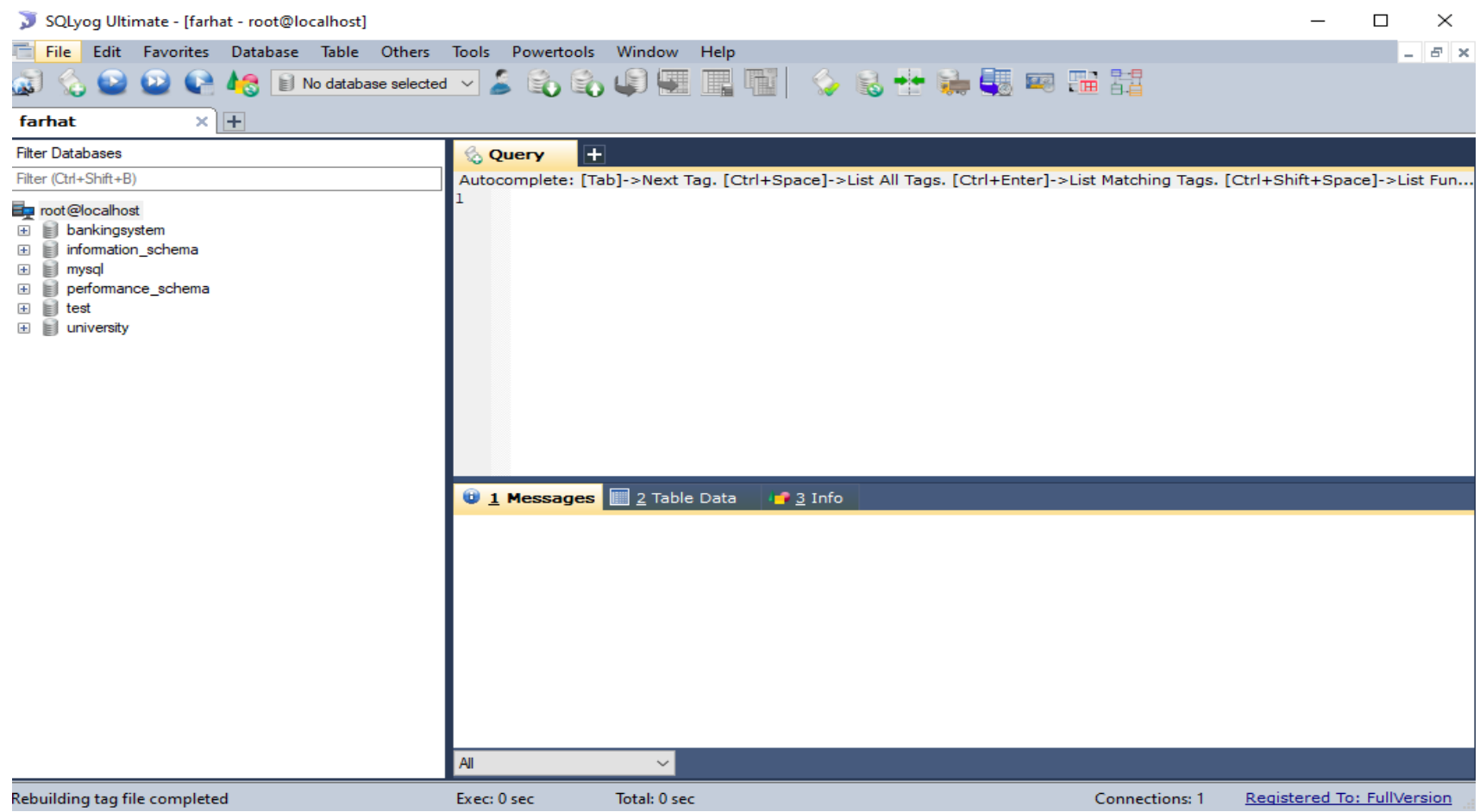

Fig. 2. Shows the SQLyog and MySQL 


\section{A. Database Structure}

Customer feedback system or Customer Review Management system is designed in a way that it must be simple and easy for the bank's customers to provide their review of employees and rate their service quality easily. As things are kept very simple for the customers and not many complicated and unnecessary questions asked from the customers because most of the time customers are in hurry to leave once they have been served by the employees of the bank. A database named Banking System was created on a local Database server. There are only two Tables created in Database Management systems for this project. Table 1 is named as 'employees' table, this table will have all the employee's list working in a bank and serving the customers, bank's high management will provide names of the employees that will be added in this table through software patches and screen setups or SQL queries. Employees table contains three columns as emp_id, emp_name, and emp_branch. emp_id will have employee's bank id numbers, employee's id must be unique in bank similarly emp_id in employees table must be unique and emp_id is marked as the primary key of the employee table. The attributes like name and branch can be the same as other employees, emp_name will contain employee's names and emp_branch will contain the bank's branch name, which particular employees are working respectively.

Table 1. Employee table structure

\begin{tabular}{|c|l|l|}
\hline emp_id & emp_name & \multicolumn{1}{|c|}{ Emp_brnach } \\
\hline 1 & MEHRAN & KARACHI \\
\hline 2 & NOOR & HYDERABAD \\
\hline 3 & ALI & JAMSHORO \\
\hline 4 & PERVEZ & LARKANA \\
\hline 5 & KHAN & KORANGI \\
\hline 6 & WALI MOHD & DADU \\
\hline 7 & FARHAT & ISLAMABAD \\
\hline 8 & AWAIS KHAN & KHAIRPUR \\
\hline
\end{tabular}

Table 2 is named as the 'reviews' table; this table will contain the actual customer's feedback on employee's quality of service and customers' real experience with the product and employee. Customers will add the data to the employee's table through software form. The review table is the main table of his database as it contains real-world reviews of customers. Review tables are the table that bounds the bank's employee's provided quality of service and customer's quality of experience. Review tables contain ten columns as review_id, emp_id, Q1, Q2, Q3, Q4, Q5, suggestion, cust_name, cust_email. Review_id is the primary key of the review table to uniquely identify the review and is auto-generated and will never be null or empty. Emp_id makes relation with employee's tables, here emp_id is considered as foreign key mapped with employee table, this makes a one-to-many relation between both the tables. That is one employee can have many reviews.

Q in columns Q1, Q2, Q3, Q4, Q5 stands for questions, these are the real-world reviews of worthy customers on the quality of service employee has provided. Q1 is mapped with the question from the front end with communication skills of the employee, Q2 is mapped with product/service knowledge of the employee, Q3 is mapped with the speed of service of the employee, and similarly, Q4 is mapped with the behavior of employee with the customer, and the last question is mapped with the overall experience of the customer with the employee they have been served by and for whom they are providing reviews.

All these five questions are mandatory and must be answered by customers who are willing to provide a review on service quality. These five questions are marked as 'not null' on a database level and have been validated on the frontend and client-side as well. Suggestion column is containing customers' written review here customers can provide their remarks on employee's provided quality of service. Although the suggestions columns can be null and are completely optional and customers can skip the suggestion field. Cust_name is mapped with the customer name from the front end and is optional; if a customer does not want to show or give her name then he/she can skip this as well similarly like the suggestions column. In any case, the employee for whom the customer has given feedback will never be able to know what the customer has written or what feedback they have given. The last column is cust_email, it contains the email address of the customer who is giving feedback or review on the customer. Cust_email is simpler to cust_name means it is optional and is not mandatory and is marked as not null on a database level and has been allowing to skip from frontend. 
Table 2. Review table structure

\begin{tabular}{|c|c|c|c|c|c|c|c|c|c|}
\hline $\begin{array}{c}\text { Review } \\
\text { id }\end{array}$ & $\begin{array}{r}\text { emp } \\
\text { id }\end{array}$ & q1 & $\mathbf{q 2}$ & q3 & $\mathrm{q4}$ & q5 & suggestion & cust_name & cust_email \\
\hline 1 & 1 & Excellent & Excellent & Excellent & Excellent & Excellent & very good & Kashif & \\
\hline 2 & 1 & Excellent & Excellent & Excellent & Excellent & Excellent & Top Class & Khalid & \\
\hline 3 & 1 & Good & Excellent & Excellent & Excellent & Good & Very Good & Samina & Samin@gmail.com \\
\hline 4 & 1 & Excellent & Excellent & Dissatisfied & Excellent & Excellent & Little Slow & Jawad & jaw@gmail.com \\
\hline 5 & 1 & Excellent & Good & Good & Excellent & Excellent & very nice & Waheed & ali@gmail.com \\
\hline 6 & 1 & Excellent & Excellent & Good & Excellent & Good & Rude & Mehar & \\
\hline 7 & 1 & Excellent & Good & Good & Dissatisfied & Excellent & Not Good & Waleed & \\
\hline 8 & 1 & Good & Excellent & Excellent & Excellent & Good & Bad & & \\
\hline 9 & 1 & Excellent & Excellent & Excellent & Excellent & Good & Good & Dilshad & \\
\hline 10 & 1 & Dissatisfied & Dissatisfied & Dissatisfied & Dissatisfied & Dissatisfied & $\mathrm{Bad}$ & & \\
\hline
\end{tabular}

\section{B. Application Development}

Application has been developed on Model, View, and Controller (MVC) design pattern, thus there is a different layer for the user interface (UI) also known as frontend, business logic, which is also known as backend. For frontend design HTML, CSS and bootstrap are used to make a good design view for the users of the application. For client-side validations and some basic logic, JavaScript has been used, whereas for backend and server-side programming Java Servlets has been used. Conventional Java database connectivity (JDBC) has been used to connect this application with the MySQL database.

\section{Server Environment}

Apache Tomcat server version 9 is used to deploy the application on the server [30, 31]. The reason behind using the apache tomcat server for deploying the application is very lightweight, open-source, free of cost, more secure and well documented. Figure 3 shows the Apache tomcat server displaying the console.
$\leftarrow \rightarrow$ C 畐
(1) (i) localhost:8080
... 可血
IIII

\section{Apache Tomcat/9.0.16}

\section{If you're seeing this, you've successfully installed Tomcat. Congratulations!}

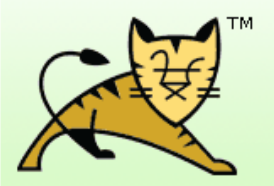

Recommended Reading:

Security Considerations How-To

Manager Application How-To

Clustering/Session Replication How-To

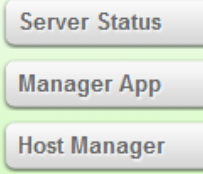

\section{Developer Quick Start}

\begin{tabular}{|c|c|c|c|}
\hline Tomcat Setup & Realms \& AAA & Examples & Servlet Specifications \\
\hline First Web Application & $\underline{\text { JDBC DataSources }}$ & & Tomcat Versions \\
\hline
\end{tabular}

\section{Managing Tomcat}

For security, access to the manager webapp is restricted. Users are defined in

\$CATALINA_HOME/conf/tomcat-users.xml

In Tomcat 9.0 access to the manager application is split between different users Read more...

\section{Release Notes \\ Changelog \\ Migration Guide \\ Security Notices}

\section{Documentation}

Tomcat 9.0 Documentation

Tomcat 9.0 Configuration

Tomcat Wiki

Find additional important configuration

information in

\$CATALINA_HOME/RUNNING. $\mathrm{txt}$

Developers may be interested in:

Tomcat 9.0 Bug Database

Tomcat 9.0 JavaDocs

Tomcat 9.0 SVN Repository

\section{Getting Help}

\section{FAQ and Mailing Lists}

The following mailing lists are available:

tomcat-announce

Important announcements, releases, security vulnerability notifications. (Low volume).

tomcat-users

User support and discussion

taglibs-user

User support and discussion for Apache Taglibs

tomcat-dev

Development mailing list, including commit messages

Fig 3. The Apache tomcat server console 


\section{Frontend UI for customer}

Front-end and client-side of Customer Review Management System is designed in a way that it must be very easy to use, and it must not take the time of worthy customer of the bank. A customer can post a review in less than a minute as it has been kept in mind that most customers of the banks are in a hurry. Customers just have to answer five questions from User-Interface designed for this system. User Interface of this customer feedback management system is kept very simple and decent and any bank can just update its plain HTML to their bank's template design. Simple HTML, CSS, JavaScript, and bootstrap were used to create and develop this system's view layers and client-side functionalities. Once the service is provided to the bank's customer by the employee of the bank and if the customer is willing to provide feedback and is ready to rate the quality of service provided to him/her by the bank's staff. They must have to answer five questions and three fields are optional, which can be skipped. Mandatory questions are multiplechoice questions (MCQ) and the customer can only choose one answer from each question. On technical terms, HTML's radio buttons have been used to provide multiple choice options to the customers. There are four levels of ratings from customers, Excellent, Good, Average and Dissatisfied/Bad. Customers can choose any of the abovementioned ratings based on their QoE with the employee, which has provided the service.

In this customer review system, we have chosen question one as 'Communication' which is mapped with Q1 on Database layer, the customer has to rate the communication skills of employee that has served him/her that is whether or not the employee of the bank has good communications skills or not and is an employee of the bank can convey the product and service information easily. Question two is 'knowledge accuracy' which is mapped with Q2 at Database level, a worthy customer of the bank will provide feedback of employee that has provided service on the knowledge of product and service employee has for what the customer had come to the bank. It would be the worst thing if an employee working as a car loan officer and has no knowledge of loan schemes and bank car loan offers.

Question three is about the 'speed of service' and this question is mapped with Q3 in Database. Question three customers have to choose the speed of service the employee has worked and solved the issues the customer is facing. If a cash offer/teller of the bank is taking too much time to withdraw cash and passing a cheque, then he will get $\mathrm{Bad} /$ dissatisfied customers review and if more than five to ten customers are giving dissatisfied feedback to an employee than that means employee speed of working is slow particularly in counting cash and then management can change the role accordingly. Question four is 'behavior' and is mapped with Q4 on the Database layer. Customers will rate the behavior of the employee and will provide feedback on the employee's attitude and manners. If an employee is rude then customers will give them dissatisfied, on the other hand, employees will always behave well with the customers as they know they will be rated on the service quality they are providing to the clients.

The bank's point of view question, 4 can be very critical, and most important as if the behavior of the employee is not good with the customer than the bank will surely lose their worthy customers and this will never be good for the bank's business. Customers who are investing their money in banks will never tolerate the misbehavior of employees. As other things can be tolerated, but not the worst behavior of employees, who are getting their salary from the profit bank is earning by investing the money they are getting from these customers. Question five is 'Over Experience' and this question is mapped with Q5 on Database level. On question 5 customers will provide their overall experience with the employee and this question can be considered the combination of all the other four questions. Suppose if the customer has provided a mixture of reviews that is excellent on question one, average on question 2, good on question 3 and similarly bad/Dissatisfied on question 4 than customers overall experience should be considered to be most important as if overall experience of the customer is bad then it will not be good for bank and employees as the bank will lose customers.

There are three other Text Fields in the form, which are optional and the customer can skip them if they want to. Unlike the five questions, these are not multiple-choice questions; they are text fields that must be filled in writing in case of a paper form or typing in case of online form. The first text field is 'suggestion' which is mapped with the suggestion column in the database layer. In the suggestion, field customers can provide any suggestions and can provide any feedback. Additionally, customers can remark them complain if they were not served well by the employee. Customers can write a positive note as well for the employee if they have been served better than their expectations. The other two fields are 'Name' and 'Email' both these filed are mapped with cust_name and cust_email columns respectively. Both fields are completely optional and customers can skip them if they don't want to show their identity or are in a hurry. Branch level or division level staff of the bank will never be able to know about the reviews, in any case, it must be kept confidential. After filling the mandatory fields, the customer will have to submit the online form through a button named 'Submit'. If the entire mandatory is answered the customer has clicked the submit button, then the customer will see a popup message on the screen as 'Thank you for your feedback'. Once the message has been removed all the filled fields will become empty and the screen will be ready to take another feedback/review from another customer. Figures 4 and 5 are the view of a User interface designed for this customer feedback management system. 


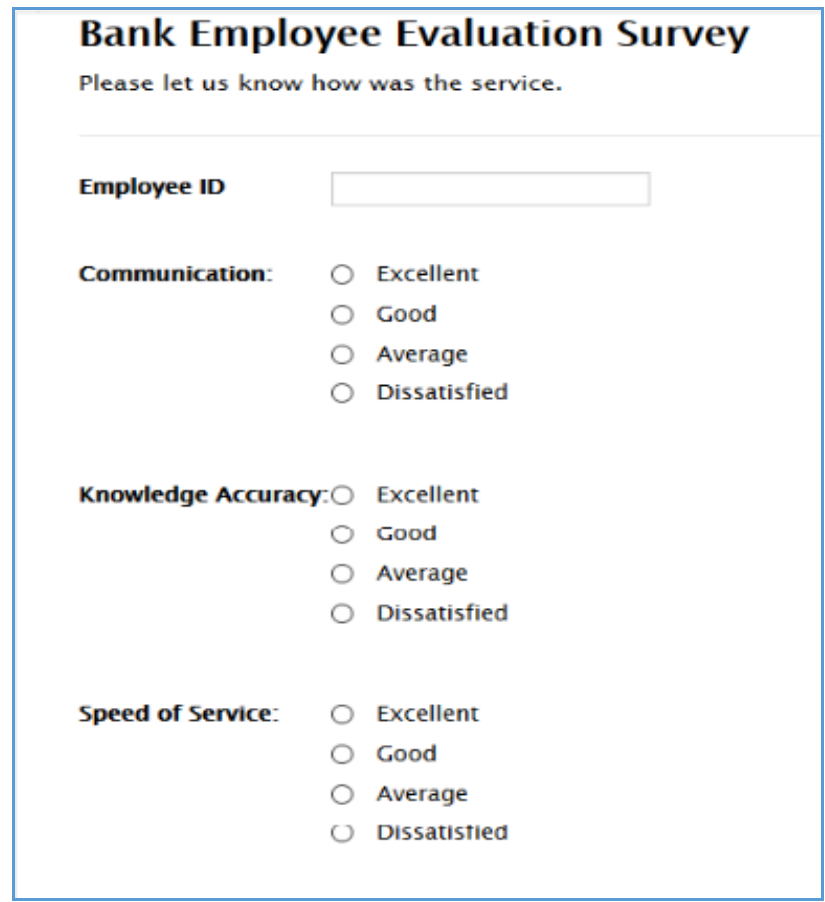

Fig 4. View of feedback page

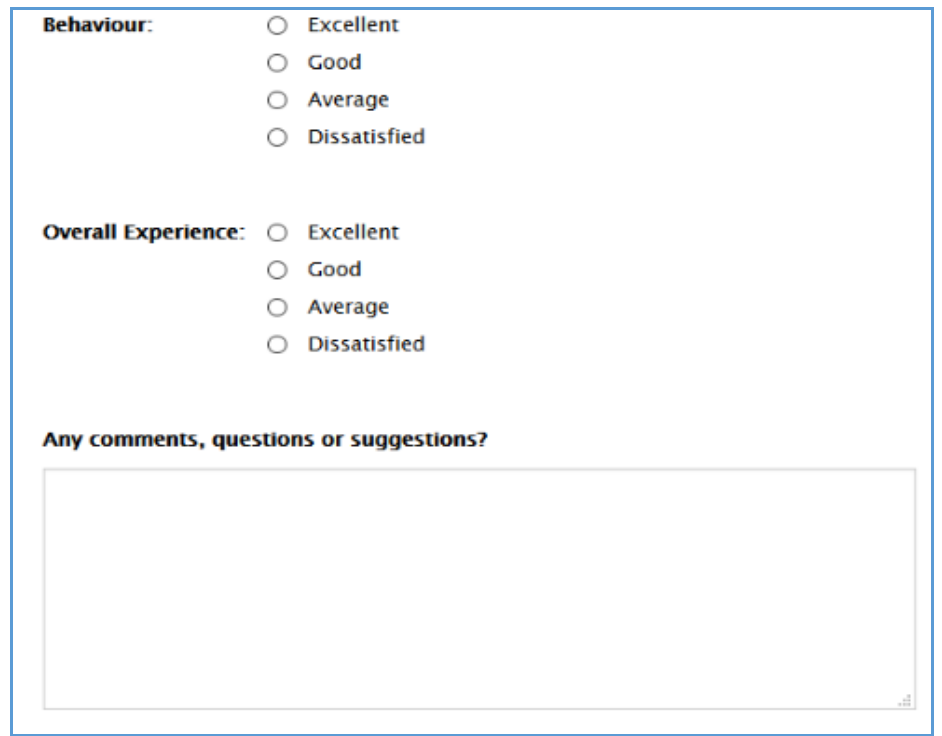

Fig 5. View of customer's User Interface

\section{Results and Discussion}

Only management-level employees and HR department employees can view the records are given in Figure 6 as it displays the real-time reviews submitted by customers of the bank on the service quality provided by the employees of the bank.

To obtain real-life results and real-time customer's reviews on service quality provided by employees of the bank, in a branch of one of the top-level banks of Pakistan this research was conducted. In must be mentioned bank only allowed taking review on one employee, whose name was kept confidential as the bank and its branch has not been disclosed to keep it confidential. Figure 7 shows the employee's QoS review based on a worthy customer's experience with the employee. 


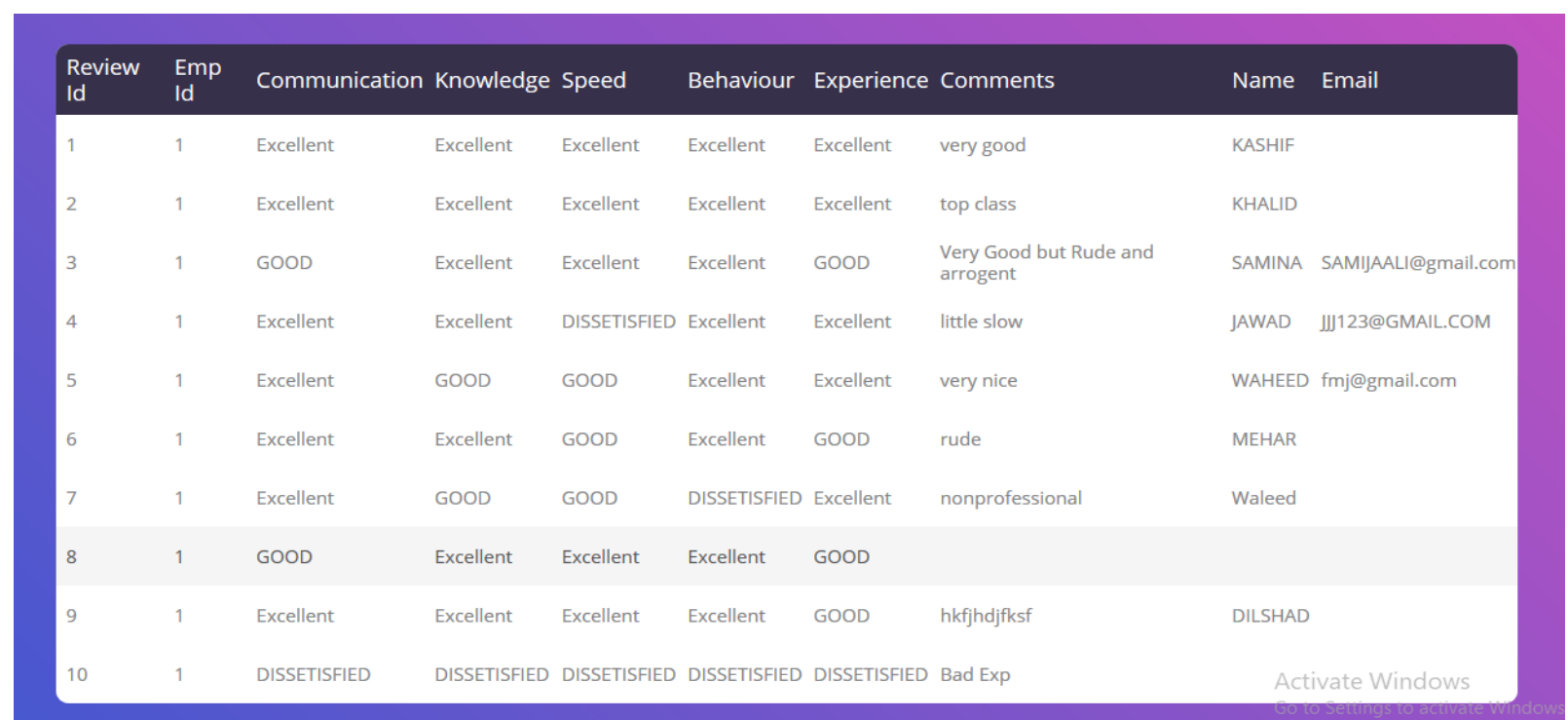

Fig 6. The management's User Interface

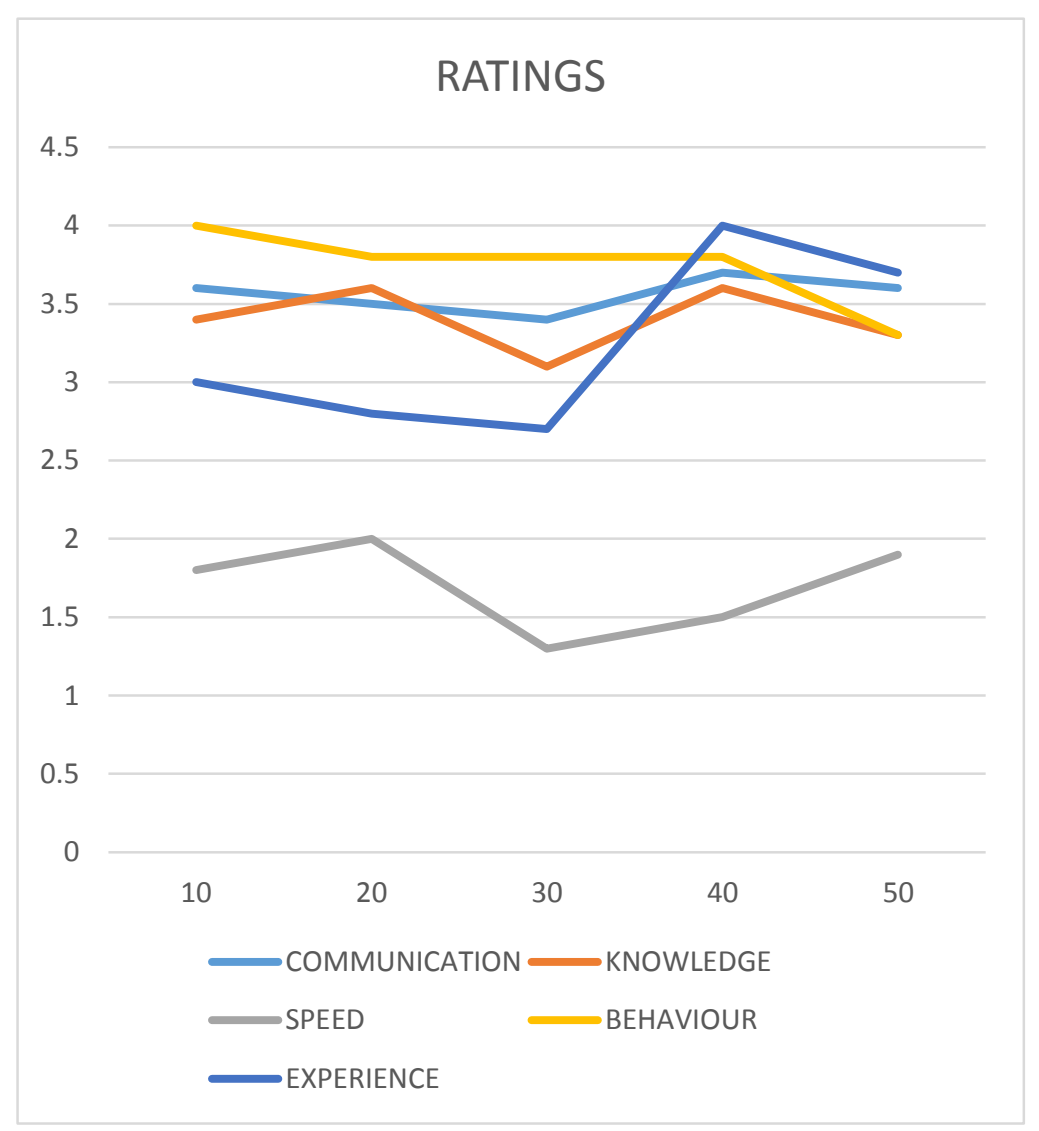

Fig 7. Management Reviews in line chart

In Figure 7, 50 customers gave reviews on their experience with the employee and they rated the employee in all the 5 categories/questions. The particular employee is getting 'excellent' to 'good' which is 4 and 3 respectively in all the questions answered by most of the customers. The result shows that the employee is lacking in his 'speed of work' where he has got 1 to 2, which is equal to dissatisfaction to average. In this case, Management now clearly can decide what they want to do to overcome an efficient employee's slow speed of work or overcome any skill the employee is lacking in management can decide whatever they want to do based on these reviews. Overall this system will help banks to create the first Customer Feedback management system in the banking domain at daily branch level activities to improve the bank's employee's performance, to provide bank's management employees flaws and strengths. to collect customer's reviews and feedbacks and to improve QoS provided by employees of the bank and to improve the 
quality of experience of customers served by the employee. The results showed that higher management of the banks can easily observe and analyze the quality of experience customers are having and the quality of service employees of the banks are providing to the worthy customers of the bank. The result of the QoS of employees of the bank is given in Figures 8, 9 and 10.

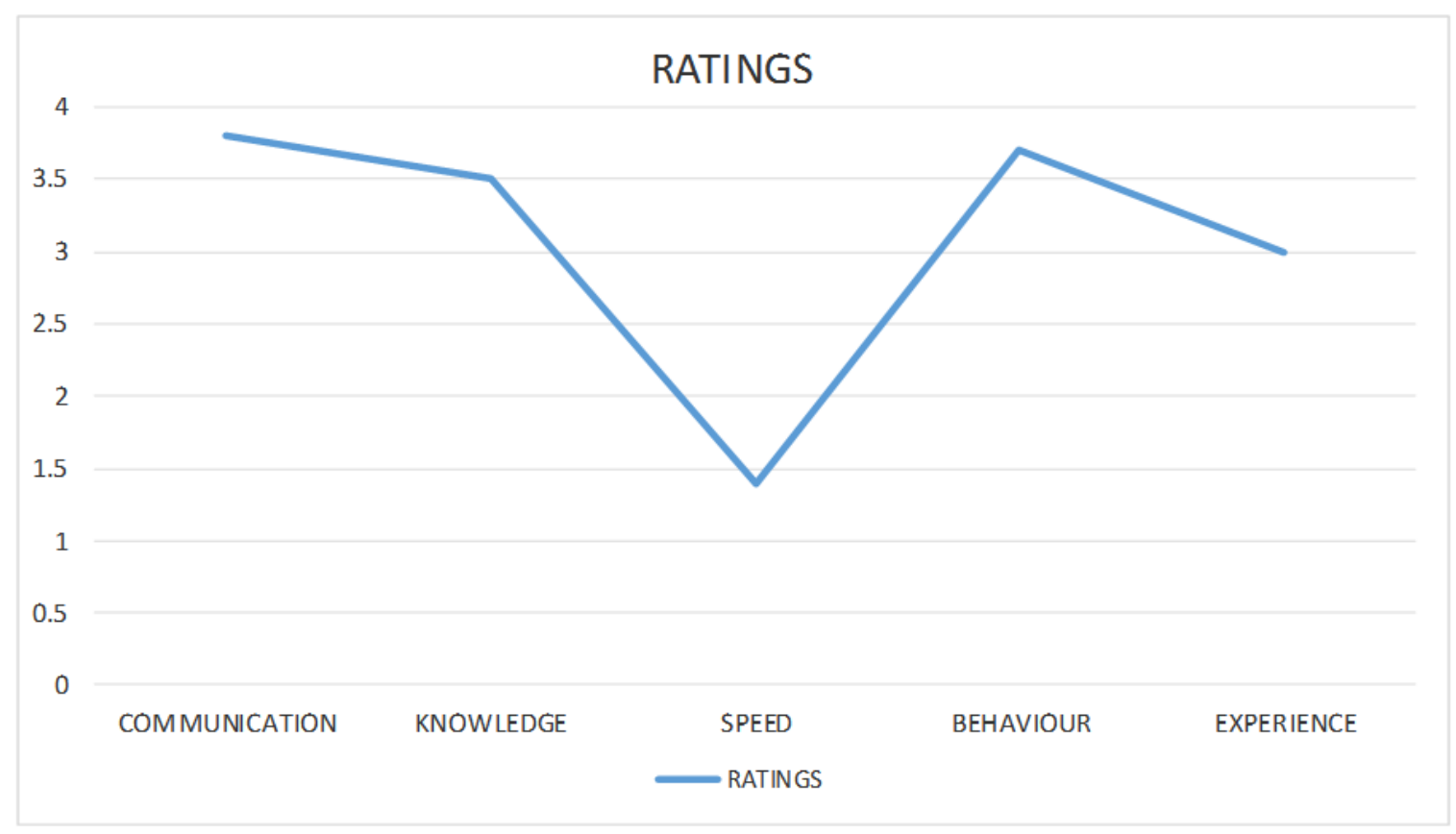

Fig 8. Management Reviews in single line chart

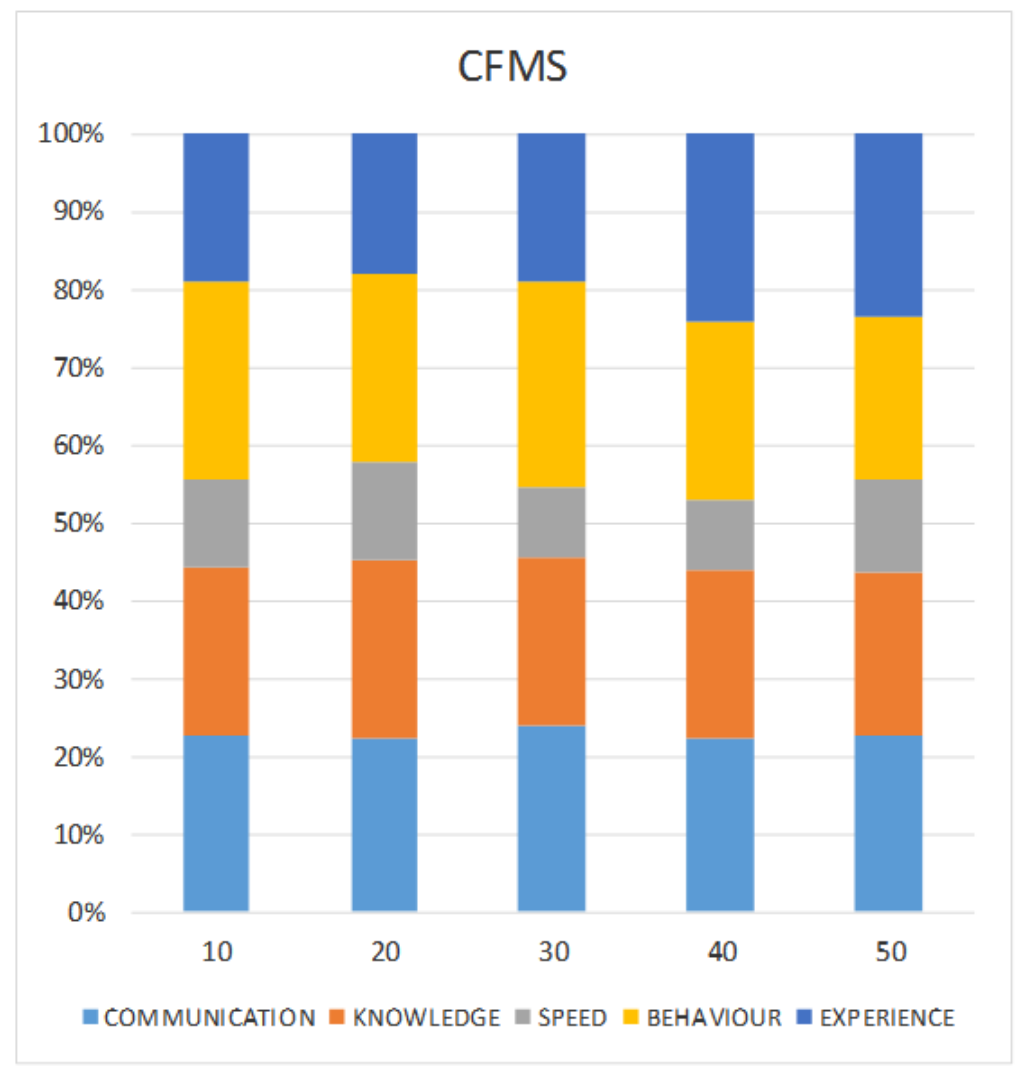

Fig 9. Shows Management Reviews in column chart 


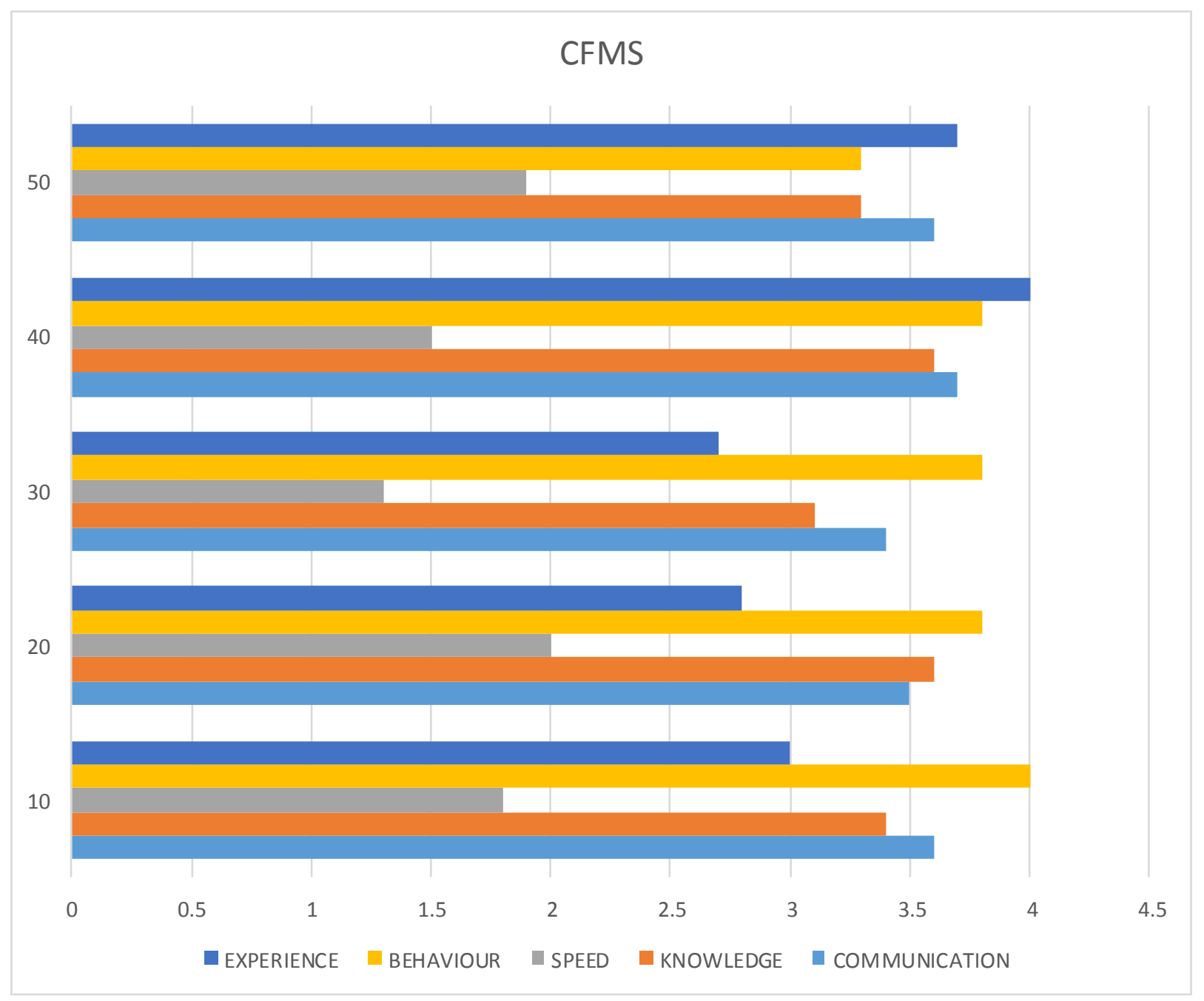

Fig 10. Shows Management Reviews in bar chart

\section{Conclusion \& Future Work}

Customer Feedback Management System will help banks in Pakistan to improve their QoS and customers will be served well and their QoE with the bank would be better. A proper application system has been developed during this research with several common questions, which have accuracy to data collecting and analysis and provide better performance to evaluate the services of bank. Customers will provide their reviews and will answer the questions provided in the form. Banks can change the questions by changing the user interface and they will not need anything else to be changed on the backend or at the database level. After implementing this proposed work management of the bank willing to implement this system can observe the performance of their bank's employees and can overcome their flaws by providing the required training. Additionally, this system could be very helpful for bank's high authorities and management to decide the annual appraisals or rewards, and can also be used to transfer one employee to another department if not improving or performing too poorly after training.

In the future, this customer feedback management system (CFMS) and research work would be used in different banks of Pakistan; one of the leading banks of Pakistan would start using this system within a year in their 750 plus branches network. In the future, banks in Pakistan would ask every customer to provide a review on the QoS provided by the employee of the bank. Additionally, the proposed system can be developed in a mobile-based version as well. Where customers once served by the employees will be given a tablet to fill a similar form. This system can be developed in both android and IOS operating system respectively.

\section{Compliance with Ethical Standards \\ Conflict of Interest:}

Authors did not have any conflict of interest.

Ethical Approval: 
Not applicable.

Informed Consent

Obtained from participants

\section{References}

[1] Barakabitze, A.A., Barman, N., Ahmad, A., Zadtootaghaj, S., Sun, L., Martini, M.G. and Atzori, L., 2019. "QoE management of multimedia streaming services in future networks: a tutorial and survey”. IEEE Communications Surveys \& Tutorials, 22(1), pp.526-565, 2019.

[2] Laghari, A.A., He, H., Khan, A., Kumar, N. and Kharel, R., "Quality of experience framework for cloud computing (QoC)”. IEEE Access, 6, pp.64876-64890, 2018.

[3] Laghari, A.A, Laghari, R. A, Wagan, A.A, and Umrani, A. "Effect of Packet Loss and Reorder on Quality of Audio Streaming." EAI Endorsed Transactions on Scalable Information Systems 7, no. 24 (2020).

[4] Laghari, A.A., He, H. and Channa, M.I., "Measuring effect of packet reordering on quality of experience (QoE) in video streaming", 3D Research, 9(3), p.30, 2018.

[5] Yang, J., Pan, Z. and Guo, L., "Coverage and Energy Efficiency Analysis for Two-Tier Heterogeneous Cellular Networks Based on Matérn Hard-Core Process", Future Internet, 12(1), p.1, 2020.

[6] Laghari, A.A., He, H., Karim, S., Shah, H.A. and Karn, N.K., "Quality of experience assessment of video quality in social clouds", Wireless Communications and Mobile Computing, 2017.

[7] Karembai, A.K., Thompson, J. and Seeling, P., "Towards prediction of immersive virtual reality image quality of experience and quality of service", Future Internet, 10(7), p.63, 2018

[8] Laghari, A.A., He, H., Shafiq, M. and Khan, A., "Application of quality of experience in networked services: Review, trend \& perspectives", Systemic Practice and Action Research, 32(5), pp.501-519, 2019.

[9] Laghari, A.A., He, H., Memon, K.A., Laghari, R.A., Halepoto, I.A. and Khan, A., "Quality of experience (QoE) in cloud gaming models: A review", Multiagent and Grid Systems, 15(3), pp.289-304. 2019.

[10] Yasin, R., Jauhar, J. and Rahim, N.F.B.A., "A Qualitative Investigation of Workplace Violence: -A Case of Female Bankers in Pakistan”, Global Journal of Management And Business Research, 2018.

[11] Khan, A.B., Shah, S.Z.A. and Abbas, M., "The Relative Efficiency of Commercial Banks in Pakistan with Respect to Size and Ownership Structure During and After Global Financial Crisis". Journal of Accounting and Finance in Emerging Economies, 4(2), pp.123-132, 2018.

[12] Rafay, A., Mohsan, T. and Sadiq, R., "Structural Mix of Credit Portfolios in Islamic Banking System: Evidence from a South Asian Economy'. Advances in Islamic Finance, Marketing, and Management”, Emerald Group Publishing Limited, pp.185-210, 2016.

[13] Habib, M., "An Analysis of the Operations of the Card Division: A Study on Mutual Trust Bank Limited", 2019.

[14] Delrose Noronha, S., "Study on the Changing Landscape of Financial Services in Indian Banking System-Opportunities and Challenges", 2017.

[15] Babai, M. and Syed, P., "Product and customer development (general banking \& mobile financial services-UCash): a study on United Commercial Bank", 2018.

[16] Hammoud, J., Bizri, R.M. and El Baba, I., "The impact of e-banking service quality on customer satisfaction: Evidence from the Lebanese banking sector", SAGE Open, 8(3), p.2158244018790633, 2018.

[17] Laghari, A.A., Memon, K.A., Soomro, M.B., Laghari, R.A. and Kumar, V., "Quality of experience (QoE) assessment of games on workstations and mobile", Entertainment Computing, p.100362, 2020.

[18] German, J.D. and Santiago, R.A.H., "Service Quality Assessment for Information Technology Department: The Case of a Higher Education Institution in the Philippines".

[19] Sehnbruch, K., González, P., Apablaza, M., Méndez, R. and Arriagada, V., "The Quality of Employment (QoE) in nine Latin American countries: A multidimensional perspective", World Development, 127, p.104738, 2020.

[20] Wang, Y., Li, P., Jiao, L., Su, Z., Cheng, N., Shen, X.S. and Zhang, P., "A data-driven architecture for personalized QoE management in 5G wireless networks", IEEE Wireless Communications, 24(1), pp.102-110, 2016.

[21] Sánchez, P.A., Luna-Ramírez, S., Toril, M., Gijón, C. and Bejarano-Luque, J.L., "A data-driven scheduler performance model for QoE assessment in a LTE radio network planning tool" Computer Networks, p.107186, 2020.

[22] Laghari, A.A., He, H., Ibrahim, M. and Shaikh, S., "Automatic network policy change on the basis of quality of experience (QoE)" Procedia Computer Science, 107, pp.657-659, 2017.

[23] Laghari, A.A., He, H., Khan, A. and Karim, S., "Impact of video file format on quality of experience (QoE) of multimedia content" 3D Research, 9(3), p.39, 2018

[24] Laghari, A.A., Channa, M.I., Laghari, K.R., Aman, M. and Memon, M., "EQOM: enhanced quality of experience (QoE) framework for multimedia services", UACEE International Journal of Computer Science and its Applications, 3(1), pp.85-89, 2013.

[25] Laghari, A.A., He, H., Shafiq, M. and Khan, A., "Assessing effect of Cloud distance on end user's Quality of Experience (QoE)", In 2016 2nd IEEE international conference on computer and communications (ICCC) (pp. 500-505). IEEE, 2016.

[26] Sochacki, G. and Pańczyk, B., "Test-Driven Development as a tool for optimizing the software development process on the JEE platform”, Journal of Computer Sciences Institute, 4, 2017.

[27] Le Guernic, G., "Experience report on the development of a specialized multi-view multi-stakeholder model-based engineering framework", In Proceedings of the 17th ACM SIGPLAN International Workshop on Domain-Specific Modeling (pp. 50-59), 2019.

[28] Weigelt, P., König, C. and Kreft, H., "GIFT-A global inventory of floras and traits for macroecology and biogeography”, Journal of Biogeography, 47(1), pp.16-43, 2020. 
[29] Heinle, C.E., Gaultier, N.P.E., Miller, D., Purbojati, R.W. and Lauro, F.M., "MetaLIMS, a simple open-source laboratory information management system for small metagenomic labs", GigaScience, 6(6), p.gix025, 2017.

[30] Piantadosi, V., Scalabrino, S. and Oliveto, R., "Fixing of Security Vulnerabilities in Open Source Projects: A Case Study of Apache HTTP Server and Apache Tomcat” In 2019 12th IEEE Conference on Software Testing, Validation and Verification (ICST) (pp. 68-78). IEEE, 2019.

[31] Aaqib, S.M. and Sharma, L., "Evaluation and Comparison of Security Mechanisms In-Place in Various Web Server Systems", In Software Engineering (pp. 441-447). Springer, Singapore, 2019.

\section{Authors' Profiles}

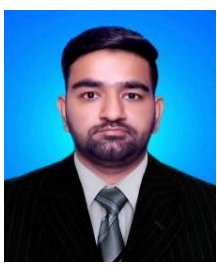

Mehran Junejo received his BS(CS) from University of Sindh (UoS), Jamshoro, Sindh, Pakistan and MS(SE) from Ilma University, Karachi, Sindh, Pakistan in 2013 and 2019 Respectively. During his MS studies Mr Mehran was working as Assistant Manager-Software in Bank Al Habib Limited. Currently he is working as Principal Software Engineer in a multinational organization named as GFK.

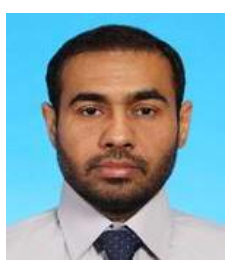

Asif Ali Laghari received the B.S. degree in Information Technology from the Quaid-e-Awam University of Engineering Science and Technology Nawabshah, Pakistan, in 2007 and Master degree in Information Technology from the QUEST Nawabshah Pakistan in 2014. From 2007 to 2008, he was a Lecturer in the Computer and Information Science Department, Digital Institute of Information Technology, Pakistan. In 2015, he joined the school of the Computer Science \& Technology, Harbin Institute of Technology, where he is now a $\mathrm{PhD}$ student. Currently he is Assistant professor in Sindh Madressatul Islam University, Karachi, Pakistan He has published more than 55 technical articles in scientific journals and conference proceedings. His current research interests include Computer networks, cloud computing, and multimedia QoE management.

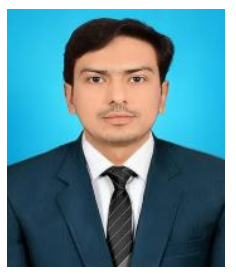

Awais Khan Jumani received his BS(CS) and MS(CS) degrees from Shah Abdul Latif (SAL) University, Khairpur, Sindh, Pakistan, in 2014 and 2018. During his MS studies, Mr. Jumani was Teaching Assistant in Dept. of Computer Science at SAL University. Currently he is an Assistant Professor at ILMA University, Karachi Mr. Jumani has published over 24 Research Articles in scientific journals and conferences. His current interests include Machine Learning, Cloud Computing and Internet of Things.

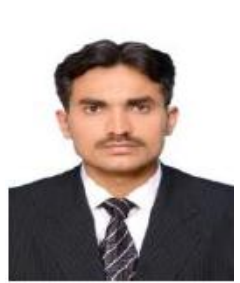

Shahid Karim received his BS degree in electronics from Comsats Institute of Information Technology, Abbottabad, Pakistan, and his MS degree in electronics and information engineering from Xi'an Jiaotong University, China, in 2010 and 2015, respectively. He is currently pursuing his $\mathrm{PhD}$ at the Department of Information and Communication Engineering, School of Electronics and Information Engineering, Harbin Institute of Technology (HIT), China. His current research interests include image processing, object detection, and classification toward optical remote sensing imagery.

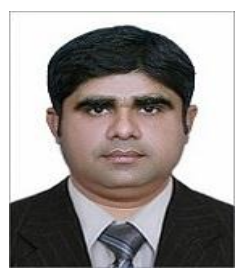

Mansoor Ahmed Khuhro has obtained his undergraduate from Information Technology Center, Sindh Agriculture University, Tandojam, he received M. E in (2012), and Ph.D. in (2017) from School of Information Science and Engineering, Central South University, Changsha, Hunan, China. Currently, he is working as Assistant Professor at Depart of Computer Science, Sindh Madressatul Islam University, Karachi. His research area includes Computer Vision, Intelligent Information Processing, Data Science and Machine Learning.

How to cite this paper: Mehran Junejo, Asif Ali Laghari, Awais Khan Jumani, Shahid Karim, Mansoor Ahmed Khuhro, " Quality of Experience Assessment of Banking Service", International Journal of Information Engineering and Electronic Business(IJIEEB), Vol.12, No.6, pp. 39-50, 2020. DOI: 10.5815/ijieeb.2020.06.04 